\title{
Liberal Arts Colleges: An Overlooked Opportunity?
}

\author{
David Damiano, Stephan Ramon Garcia, and Michele Intermont \\ Communicated by Steven J. Miller
}

\section{Introduction}

Liberal arts colleges have been part of the American academic landscape almost since the beginning of higher education in the United States; the oldest were founded in the late 1700s. They are largely an American invention, although there are fledgling liberal arts colleges being established around the world as we write. US News \& World Report lists more than 175 institutions in its ranking of National Liberal Arts Colleges, and there are national organizations for both private (Consortium of Liberal Arts Colleges) and public liberal arts colleges (Council of Public Liberal Arts Colleges).

Liberal arts colleges, which typically enroll at most a few thousand students, are known for their attention to teaching and mentoring undergraduate students. These colleges are frequently residential, with a majority of students living on campus. They usually do not have graduate or professional programs, although some of them do. Liberal arts colleges aim to produce well-rounded graduates, armed with general intellectual skills rather than specific vocational skills.

The smaller, more intimate environment of liberal arts colleges shapes the experiences of the faculty as well as the students. As faculty members at three substantially different liberal arts colleges in different regions of the country, we would like to share our experiences with the broader mathematical community. This article is a brief overview of the opportunities, rewards, and challenges of working at a liberal arts college.

David Damiano is professor of mathematics at the College of the Holy Cross. His email address is ddami ano@holycross. edu.

Stephan Ramon Garcia is associate professor of mathematics at Pomona College. His email address is stephan.garcia@ pomona.edu.

Michele Intermont is associate professor of mathematics at Kalamazoo College. Her email address is intermon@kzoo. edu.

For permission to reprint this article, please contact:

reprint-permission@ams .org.

DOI: http://dx.doi.org/10.1090/noti1381

\section{Teaching at a Liberal Arts College}

At a liberal arts college, teaching is as important as, if not more important than, research. This is reflected in the daily experience, which revolves around interactions with undergraduates. The time spent in the classroom is interspersed with office hours (Figure 1), although students are likely to drop by any time the office door

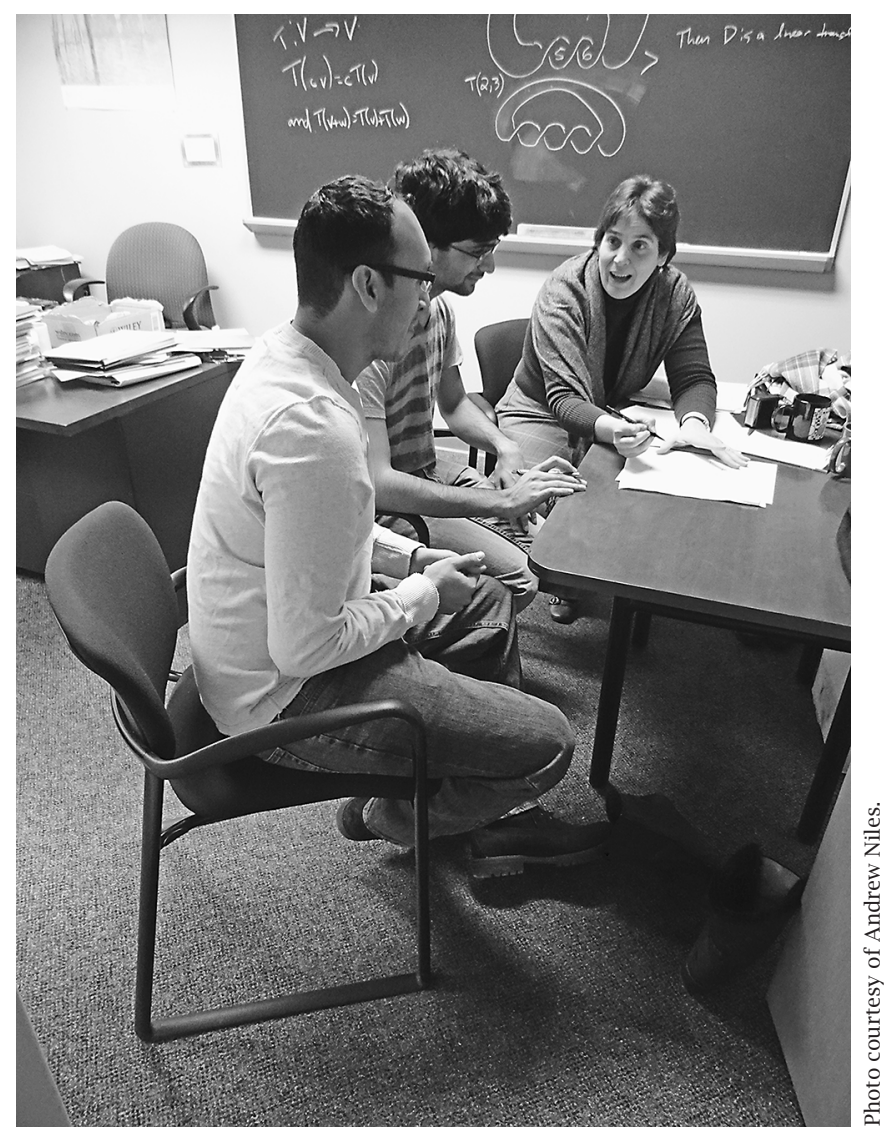

Figure 1. The third author with students during office hours. 


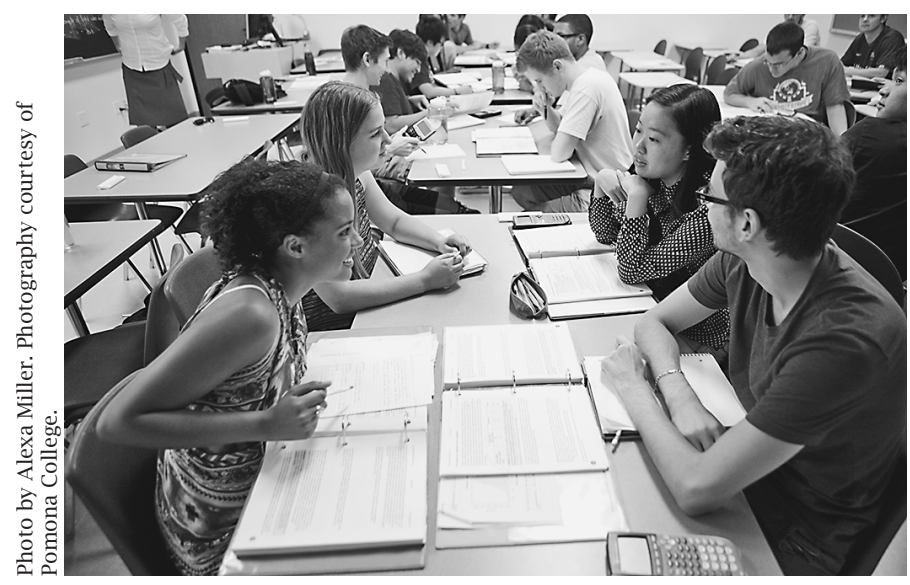

Figure 2. Pomona College students working on an in-class assignment.

is open. Faculty-student interaction outside the confines of the classroom or office is also common. There may be departmental lunches, a Putnam seminar, or an undergraduate colloquium, although there are many other possibilities. For instance, each semester the Pomona College mathematics department holds an overnight retreat at the college's cabin in the nearby San Jacinto mountains. At Holy Cross, the Math and Computer Science Club holds the weekly Tea and Games get-together and sponsors the annual $\mathrm{Pi} \mathrm{Mu}$ Epsilon banquet, both of which are for students and faculty. Kalamazoo math students and faculty take occasional hikes along a trail and walk to the neighboring university for math events.

Faculty members teach a mix of courses each year. This likely includes lower-level courses and one or two intermediate (e.g., mulitvariable calculus and linear algebra) or upper-level courses (e.g., abstract algebra and real analysis). One can even teach an upper-level topics course as staffing allows. Class sizes are often capped around thirty, with more advanced courses sometimes significantly smaller. Faculty members grade exams and, in many instances, the homework in upper-level courses. However, it is not uncommon to have math majors grade homework for lower-level courses.

Although some introductory courses might have department-mandated syllabi, there is generally a great deal of freedom in designing syllabi and choosing pedagogical approaches. Small class sizes make it possible to employ various active-learning strategies, including group assignments (Figure 2), projects, and oral presentations. Since there are no graduate teaching assistants, students are inclined to attend office hours, either individually or in groups.

The terms "lower-level course" and "nonmajors course" at a liberal arts college do not refer to business calculus, college algebra, or precalculus. Those courses are probably not even in the course catalog at some liberal arts colleges. Instead, the introductory calculus sequence serves students majoring in all disciplines. Institutions may also offer a noncalculus course which meets a quantitative literacy requirement. The parameters of such

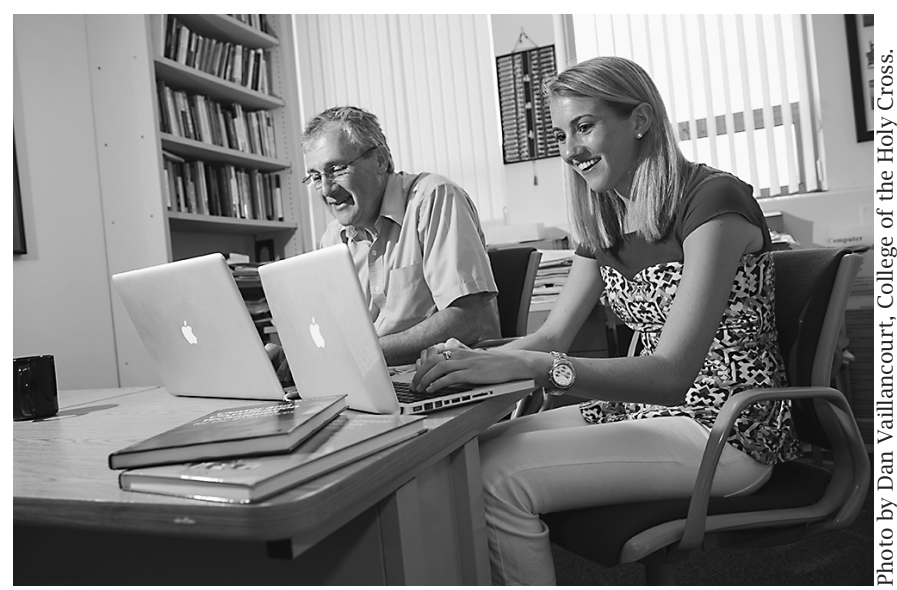

Figure 3. The first author with a research student.

courses often allow enough degrees of freedom for faculty members to tailor them to their interests.

There is a great deal of faculty ownership of the curriculum. Faculty members are concerned about how courses and departmental activities fit together as a whole and convey the dynamic nature of mathematics. Discussions often cross departmental boundaries in pursuit of educational goals. The experience that nonmajors have in the department is also of concern; there is an effort to ensure that students who will take only one math course have a positive and enlightening experience.

Working with individuals or

there is small groups during the academic

... There is year is common. This can be generally $a$ in the context of a focused regenerally a search project, senior thesis, or great deal of independent study course (Figure freedom in designing 3). Such small-scale interactions warding experiences for the third syllabi and choosing pedagogical approaches. author, who has held some small, informal seminars over the years; exploring some of the key ideas of mathematics with a small group of motivated and interested students proved to be a great source of energy.

\section{First-Year Seminars}

Many liberal arts colleges, including Holy Cross, Kalamazoo, and Pomona, feature opportunities to teach outside the standard mathematics curriculum. One can develop courses for nonmajors on topics where quantitative literacy and the interests of the instructor overlap, such as sports and statistics, and it is sometimes possible to team-teach courses with colleagues from other disciplines. The most common opportunity, however, is to teach a first-year seminar.

First-year seminar programs have a variety of incarnations, but most feature small, discussion-based courses 
that reflect interests or topics not in the yearly mathematics course offering. Can Zombies Do Math?, Rap Music, Privacy in the Digital Age, and Ciphers and Heroes are some of the titles of seminars taught by mathematicians at our institutions recently.

Most first-year seminars have goals beyond content, such as developing writing and presentation skills and acclimating students to collegiate expectations. There is often institutional support for instructors who are new to this venture, such as guidelines to assess writing, librarians who teach students how to perform academic research in the library, and informal meetings with other seminar faculty to discuss their experiences. The third author has taught in this program several times. The experience included a mentoring aspect not present in other courses which produced a rewarding esprit de corps. She also enjoyed the opportunity to develop a seminar course that indulged her interest in writing and her enthusiasm for topology.

\section{Research at Liberal Arts Colleges}

Research is an essential part of professional development at liberal arts colleges, and all faculty members are expected to engage in research; the exact requirements vary between institutions. Maintaining the balance between research and teaching is a concern; the challenges of finding time to keep up with research must be addressed by each individual.

Some liberal arts colleges have, in the last decade or two, reduced their teaching loads in order to encourage their faculty to be more productive. Research expectations for new faculty members, who may have lower teaching loads than their predecessors did, are often higher than they were several decades ago. Most liberal arts colleges greatly prize those who are able to regularly incorporate undergraduates into their research.

Research expectations are often higher at liberal arts colleges with lower teaching loads than at those with higher loads, although there
Most liberal arts colleges greatly prize those who are able to regularly incorporate undergraduates into their research. can be significant variations between otherwise comparable institutions. Output that might be sufficient for tenure at one institution might be insufficient to be hired at another. Each liberal arts college is different, and it is difficult to make any blanket statements regarding research expectations, except perhaps that research expectations at liberal arts colleges generally do not rise to the level of those encountered at R1 institutions.

Although external research grants are not expected for tenure or promotion, there are National Science Foundation (NSF) programs that support research at primarily undergraduate institutions. These include the Research in Undergraduate Institutions (RUI) and Research Opportunity Awards (ROA) programs. For instance, several faculty members at Pomona and Holy Cross are supported by RUI grants.

Faculty members at liberal arts colleges are active in the AMS, MAA, and other professional organizations. They serve as editors of journals and on elected and appointed committees. For instance, the president-elect of the Association for Women in Mathematics (AWM) is from Pomona College, the editor-in-chief of the Notices of the AMS is from Williams College, and the president of the MAA is from Harvey Mudd College. In fact, the second author is on the editorial board of the Proceedings of the AMS. In the last ten years, Holy Cross (2011), Macalester College (2010), and Claremont McKenna College (2008) each hosted AMS Sectional Meetings.

One key difference between life at a liberal arts college and at a large, research-oriented institution is that faculty members must actively seek out research opportunities. Visiting scholars do not appear in the department as regularly as they do at research-intensive institutions. Liberal arts colleges typically do not boast specialized research seminars in which like-minded researchers keep up with the latest developments in the field, and there are no graduate seminars. Many liberal arts colleges, however, do have a colloquium series. Some have a colloquium requirement for their students and hence a habit of regular speakers; others have a more spontaneous approach. While the talks are geared toward undergraduate mathematics majors, for the faculty they provide accessible talks on a variety of topics and, more importantly, opportunities to network within the larger mathematical world. For many liberal arts colleges, neighboring research institutions may also be a source of inspiration; in such a setting, faculty members can attend seminars and collaborate with colleagues in research-oriented departments.

\section{Undergraduate Research}

Undergraduate research is now widely embraced by liberal arts colleges. While some colleges, such as Wabash College, Hope College, and Lafayette College, have their own NSF-funded Research Experience for Undergraduate (REU) programs, many now have college-wide undergraduate research initiatives that include summer research components. These are typically funded by established institutional budget lines and institutional grants, supplemented occasionally by individual grants. The summer programs provide experiences similar to federally funded REUs: students work with a faculty mentor, either individually or in small groups (Figure 4). 


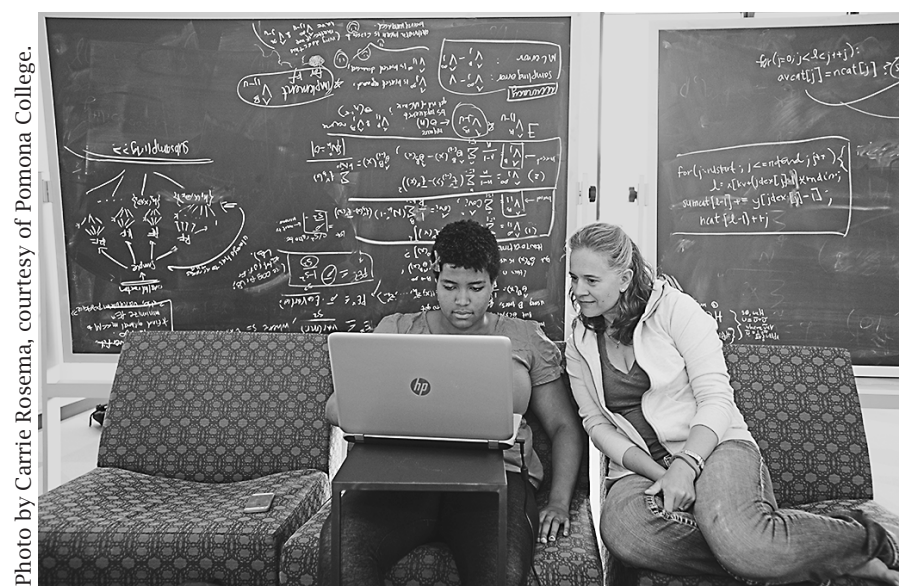

Figure 4. Pomona College professor Johanna Hardin working with a research student.

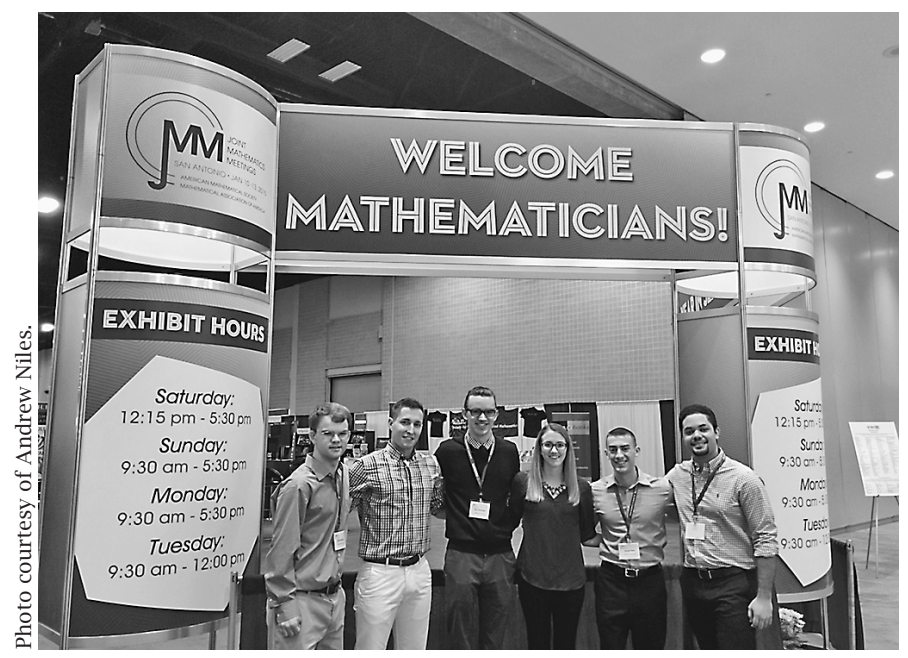

Figure 5. Holy Cross student presenters at the 2015 Joint Mathematics Meetings.

In-house summer opportunities can continue during the academic year in the form of independent study projects, capstone projects, or senior theses, or a research project might begin during the academic year as a senior thesis project or an independent study course. There are many opportunities for students to present posters or give talks on their work at regional conferences and national meetings, including the Joint Mathematics Meetings (Figure 5). In addition, schools that support internal research programs often have in-house poster sessions or conferences that bring together all the undergraduate research at the institution. Depending on the quality of the work, the students and mentor may write up the results for publication.

The second author has written dozens of articles with student coauthors; the vast majority of these articles stem from senior theses or academic-year research projects. Although many of these students went on to top graduate

\section{One of the most rewarding} aspects ... is being able to reach out to students who ... might not envision themselves doing research or mathematicians. becoming

programs and several have earned NSF Graduate Research Fellowships, most of them did not start college intending to major in mathematics. One of the most rewarding aspects of working at a liberal arts college, in the opinion of the second author, is being able to reach out to students who, without individual guidance, might not envision themselves doing research or becoming mathematicians.

At some schools, such as Pomona and Kalamazoo, every mathematics major must write a senior thesis. Because the mathematics major is Pomona's most popular major, each faculty member supervises three to five senior theses per year. In contrast, at Holy Cross no more than a handful of students write a thesis in a given year. While these theses may be expository, many advisors pose projects involving original research, some of

which will lead to publications. Although a thesis is not required at Holy Cross, all students are required to complete a project-based course in which students work in small groups on a project related to the topic of the course. Many involve original problem solving related to new examples or applications of mathematics. There are, of course, a wide variety of programs leading to student projects. For example, Carleton College's Comps program for mathematics and mathematics/statistics majors provides the flexibility of small group or individual work leading to a public presentation and a possible paper.

The time that faculty members spend on undergraduate projects during the academic year varies. Some meet with students once a week as a graduate advisor might, others meet more regularly as one does in an undergraduate course. While the students are talented and desire to be independent, they are not advanced graduate students. Supervisors should be ready to spend more time with their students as needed. Project topics can vary; they might be outgrowths of course-related projects that are essentially for the benefit of the student or they might be in areas that are central to the supervisor's own research. While theses and projects are time consuming for faculty advisors, they can also lead to stimulating interactions with students and can lead to new research directions.

\section{Diversity}

One of the challenges for many liberal arts colleges is diversifying the ethnic and socio-economic profile of their campuses. Among other issues, these institutions are simply not well known among many immigrant communities 


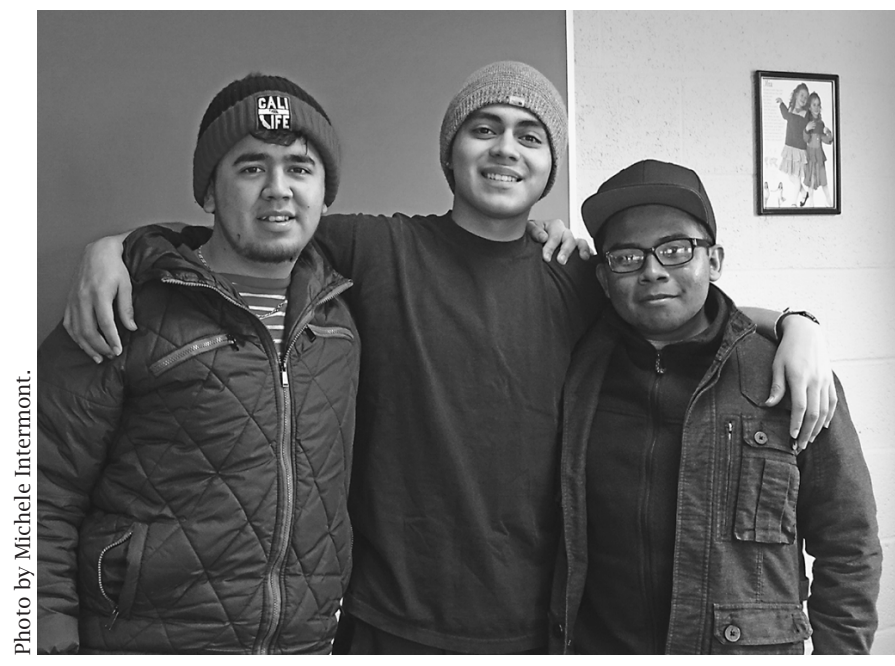

Figure 6. Some of the students in Kalamazoo's NSF STEM scholar program.

and underrepresented groups. For example, the second author is the son of immigrant parents and grew up in California but had never heard of the Claremont Colleges until he was on the job market after his postdoc. Over the last decade many liberal arts colleges have made strides in the direction of diversification, and they continue to work toward that goal.

The Posse Foundation is an important national player in promoting underrepresented students in higher education; roughly half of the fifty-three Posse partner institutions are liberal arts colleges. Posse partners with schools to identify and bring to campus students who might otherwise be overlooked in the admissions process. A cohort of talented students from public schools in a large urban area (e.g., Chicago, Los Angeles, or Miami) arrive on a campus together and navigate their four years together under the close mentorship of a faculty member. The Posse Scholars graduate from college at a rate of about 90 percent nationally.

Depending on geography and regional demographics, some liberal arts colleges have devised their own outreach programs for bringing students from underrepresented groups to campus. These may start with college preparatory or educational events, with the hope of eventually enrolling some of these students. They likely include programs to provide academic and social support on campus for their students from underrepresented groups.

Pomona College recently introduced the Pomona Scholars of Mathematics (PSM) program, a cohort model of holistic advising for students from traditionally underrepresented groups in the mathematical sciences. The PSM students enter the college with a strong interest in mathematics-based disciplines (e.g., mathematics, statistics, physics, economics, and computer science). Faculty members work closely with about sixteen students, meeting weekly with each individually. The entire PSM cohort meets as a group over lunch every week to discuss topics of interest or to interact with an outside speaker. This proactive advising and community building allows PSM students to immediately feel at home in the mathematics department. Kalamazoo College has a similar program, funded by the NSF, for underrepresented students in all STEM fields (Figure 6).

It is worth noting that while the "sticker price" of attending a liberal arts college is generally high, many colleges provide generous financial aid for students. Some liberal arts colleges have "need-blind" admissions; that is, they accept students regardless of financial need. A few of these liberal arts colleges are committed to meeting demonstrated financial need with loans or scholarships.

\section{So You Want to Work at a Liberal Arts College?}

A premise of this article is that liberal arts colleges are something of an unknown quantity for people at research universities. Graduate students and recent $\mathrm{PhDs}$ may be unaware of the career opportunities at liberal arts colleges and how best to prepare for them.

While some liberal arts colleges may consider new $\mathrm{PhDs}$ for tenure-track positions, they all prefer candidates who have led their own classes, who have taught courses beyond calculus, and who have developed an independent research trajectory. Most universities provide programs to help graduate students develop their teaching. Whether these are run by the mathematics department or by the university, they likely provide instruction on best practices as well as opportunities for critiques of teaching. Many departments provide opportunities for interested graduate students to take on more significant teaching responsibilities, such as teaching an advanced course. "Significant" here refers to the quality of teaching experience rather than the quantity.

In addition, liberal arts colleges look for some indication that an applicant knows the nature of the position. The cover letter will be read very carefully; it should be more than a perfunctory announcement of the fact that the applicant is applying for the position. Instead, the applicant should address his or her interest in a professional atmosphere as described in this article. A cover letter which also conveys familiarity with some of the features of the particular institution will be noticed. The teaching statement will be read carefully, and the research statement will be read with an eye toward assessing how well an applicant communicates with a nonspecialist.

Graduate students might find a recent trend at liberal arts colleges interesting: the creation of postdoctoral positions which carry a reduced teaching load. These provide an opportunity to develop one's teaching while protecting some time for research. Liberal arts colleges view these as a means of recruitment and as a method
The balanced nature of ... professional expectations is the centerpiece of working at a liberal arts college. 


\section{Sntroduccing a NEW \\ AMS Member Benefit}

\section{OAMS EARLY VIEW}

Early View allows individual AMS members to read peer-reviewed and accepted article manuscripts long before they appear in published form. Articles in Early View will be available until replaced by their final copyedited and proofread versions. Articles will be tagged with a DOI that will carry through to their final versions, making it easy to cite them in your research.

The Early View system will launch with these four journals:

- Journal of the American

Mathematical Society

- Mathematics of Computation

- Proceedings of the American

Mathematical Society

- Transactions of the American Mathematical Society

Start using AMS Early View today! www.ams.org/ams-early-view

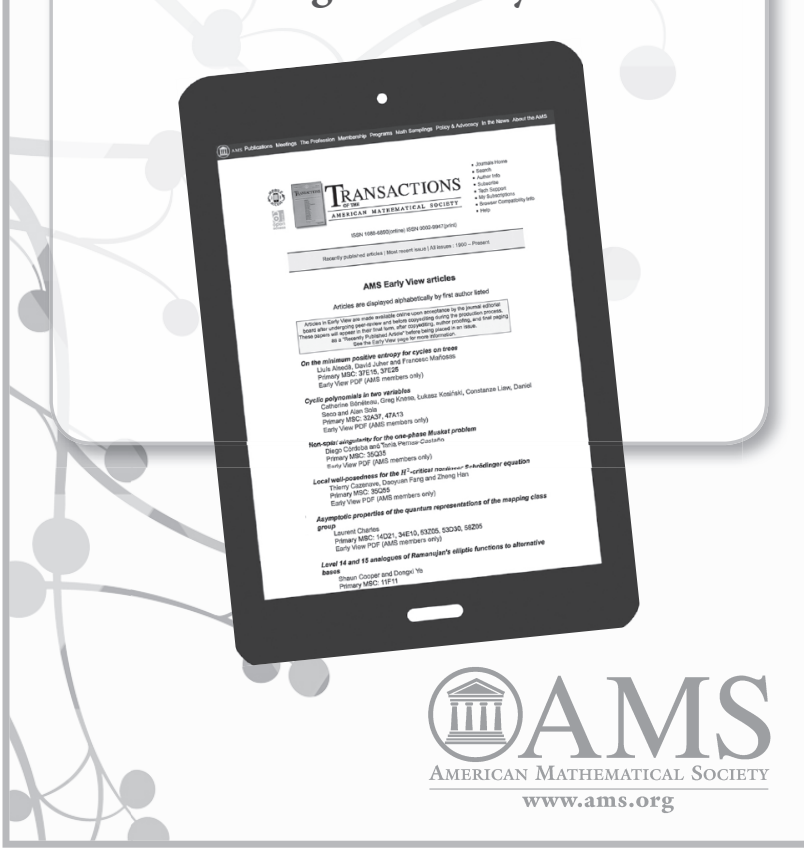

of providing potential candidates for tenure-track positions time to hone their skills beyond the structure of graduate school.

Although teaching at a liberal arts college is not for everyone, liberal arts colleges provide a stimulating environment in which both teaching and research are appreciated and supported throughout one's career. Indeed, the balanced nature of those professional expectations is the centerpiece of working at a liberal arts college. This has been true for the authors, who are at different stages of their careers and at substantially different liberal arts colleges; it is also true for many of our colleagues.

We hope some of our readers will consider joining us and that all our readers can appreciate the attractions of careers at liberal arts colleges.

\section{Biographical Sketches}

DAVID DAMIANO has been at the College of the Holy Cross since 1984 . He was trained as a topologist, and in the past decade he has pursued projects in applied mathematics, including immunological modeling and computational topology. He has been extensively involved in undergraduate research and the mentoring of majors as well as mentoring minority students. He was the recipient of the college's Distinguished Teacher of the Year Award in 2011.

StEPHAN RAMON GARCIA has been at Pomona College since 2006. He is the author of two books and over sixty research articles in operator theory, complex analysis, matrix analysis, number theory, discrete geometry, and other fields. Many of these publications are with undergraduates. He received three NSF research grants and five teaching awards from three different institutions.

MichelE INTERMONT has been at Kalamazoo College since 1998. She is an algebraic topologist. Her interests are in homotopy theory and, more recently, in topological data analysis. She has taught in the college's freshman seminar program and directed several undergraduate research projects. She has also served in the leadership of the Michigan section of the MAA. 